\title{
Priorities for Medical Marijuana Research from the Perspective of Physicians, Dispensary Owners/Staff, and Patients: A Survey Study
}

\author{
Jennifer Jean-Jacques ${ }^{a}$ Robert Cook ${ }^{a}$ Almut G. Winterstein ${ }^{a}, b, c$ \\ Amie Goodin $^{b}$ Joshua D. Brown ${ }^{b, c}$ Sebastian Jugl ${ }^{b, c}$ Yan Wang ${ }^{a}$ \\ aDepartment of Epidemiology, University of Florida, Gainesville, FL, USA; ${ }^{b}$ Department of Pharmaceutical Outcomes \\ and Policy, University of Florida, Gainesville, FL, USA; 'Center for Drug Evaluation and Safety, University of Florida, \\ Gainesville, FL, USA
}

\section{Keywords}

Medical marijuana $\cdot$ Research priorities · Survey $\cdot$ Cannabis . Education

\begin{abstract}
Objective: More patients are turning to medical marijuana as an alternative treatment, yet there are apparent knowledge gaps on the risk benefit of medical marijuana for a variety of indications. This study aimed to determine the priorities for medical marijuana research from the perspective of multiple stakeholders including patients, clinicians, and industry representatives. Methods: An anonymous survey was administered to attendees of the 2019 American Medical Marijuana Physicians Association annual meeting in Orlando, Florida. Respondents completed the survey on paper or smartphone via Qualtrics. The survey included questions on demographics and medical marijuana research priorities under the following broad categories: clinical conditions, safety issues, marijuana types, populations, and others. Results: Forty-six participants ( $56.5 \%$ female, mean age $=51.6$ \pm 14.1 ) responded to the survey. A majority were medical marijuana qualified physicians in Florida (56.5\%), 30.5\% other physicians or clinicians, and $21.7 \%$ medical marijuana pa-
\end{abstract}

tients (multiple choices allowed). The top conditions prioritized for research by this group were chronic pain, cancer, and anxiety, and the top priority safety issues were dosing/ product choice, complications from smoking/vaping, and drug interactions. Regarding marijuana types, the group prioritized research on THC/CBD ratios, different modes of consumption, and terpenes. Conclusions: Findings from this survey indicate that medical marijuana stakeholders perceived a broad range of research topics as priorities. More research is needed to advance the evidence in these areas and provide guidance to patients, physicians, and the medical marijuana industry.

(c) 2021 The Author(s).

Published by S. Karger AG, Basel

\section{Introduction}

Medical marijuana (MM) is increasingly used as an alternative or adjuvant treatment for a variety of proposed indications. Several countries have legalized marijuana for medical use [1], and 36 states plus 4 US territories (Guam, Puerto Rico, District of Columbia, USA, and Virgin Islands) have done the same, with some states carrying strict restrictions (i.e., allowing for only low-THC

C 2021 The Author(s)

Published by S. Karger AG, Basel

This is an Open Access article licensed under the Creative Commons Attribution-NonCommercial-4.0 International License (CC BY-NC) (http://www.karger.com/Services/OpenAccessLicense), applicable to the online version of the article only. Usage and distribution for commercial purposes requires written permission. 
and high-CBD products) [2]. Despite its increased use, current research on MM is limited. There is a need for more substantial evidence on MM and its effects on health to provide stakeholders (e.g., policy makers, physicians, and patients) with the information they need to make informed decisions regarding its use.

Several recent studies have assessed the attitudes, opinions, knowledge, and practices of healthcare providers regarding MM use. Findings suggest knowledge gaps exist in areas such as dosing [3], product types [3], endocannabinoid system (ECS) $[4,5]$, and effectiveness of marijuana on certain qualifying conditions [6]. Providers have also reported a lack of guidance on dosing $[5,7]$ and inadequate research [8] as barriers to their clinical decision-making. One study found that $52 \%$ of oncologists who reported recommending MM felt they had insufficient knowledge to make a recommendation [9]. Many providers call for more rigorous scientific research on MM $[3,5]$ and quality continuing education/training [8] in this area, so that they may feel more comfortable in making recommendations.

To our knowledge, only one other study has explored opinions on research priorities for MM in the USA. A 2017 survey of members of the California Pharmacy Association found that a majority were interested in pain management, dosage levels, and effects on specific diseases as priorities for research [3].

With the apparent knowledge gaps among those who recommend or use $\mathrm{MM}$, it is important to investigate the areas most in need for research and to remain engaged with the various stakeholders in the cannabis research agenda setting. The primary goal of this study was to gauge perceived research priorities related to specific clinical conditions, safety issues, marijuana types, and study populations from the perspective of MM physicians, dispensary owners/staff, and patients to inform future MM research.

\section{Methods}

\section{Recruitment}

Participants were recruited using convenience sampling. We distributed an anonymous survey at the American Medical Marijuana Physicians Association annual meeting, conference, and tradeshow held in Orlando, FL, USA, on October 4, 2019, to October 5, 2019. An announcement was made in the main conference room to inform meeting attendees about the survey. The attendees who approached the booth representing the Florida state-funded academic research organization known as the Consortium for Medical Marijuana Clinical Outcomes Research (hereafter, the "Consortium") received information about the Consortium and were asked if they would like to complete a survey about research priorities for MM. Participants were eligible if they were 18 years or older. Those who said yes, they would like to complete the survey, were given a paper survey and told to return it to the booth by the end of the day on October 5 . Written informed consent was not obtained because this was a completely anonymous survey. They were also able to take copies of the survey to their companions who were also in attendance; however, each participant was required to turn in their survey themselves; they were not allowed to turn in surveys on the behalf of others. Participants were not compensated for their participation. However, those who turned in their paper surveys received a small promotional item as an incentive (i.e., portable phone charger or stress ball). Attendees also had the option of completing the survey electronically by scanning a $Q R$ code to reach the Qualtrics version of the survey on their smartphones. This study was approved by the University of Florida Institutional Review Board.

\section{Measures}

A 22 -item questionnaire was developed by the research team to assess 3 main areas: (1) demographics (e.g., occupation, age, gender, and FL resident status), (2) MM professional experience, and (3) MM research priorities. The full survey is provided in online suppl. Material (see www.karger.com/doi/10.1159/000518105 for all online suppl. material). For research priorities, a total of 42 topics under 5 broad categories of MM research (i.e., research on a specific medical condition, safety issues, different types of MM, study populations, and other potential areas for clinical research) were listed for participants to rate their importance, using a 4-point Likert-type scale ranging from "least important" (1) to "most important" (4). The topics included were based on the authors' research experience and review of the literature. Participants were allowed to skip questions that they did not want to answer.

\section{Statistical Analysis}

Data collected using the paper-based survey were entered into Qualtrics to merge with those collected electronically via Qualtrics. Data analysis was performed using Statistical Analysis System 9.4 (SAS). Descriptive analysis was used to summarize participant characteristics (e.g., mean, standard deviation, frequency, and percentage), and research priority ratings were reported as the mean and standard deviation of the priority ratings for each condition.

\section{Results}

Our sample included 46 participants (43.5\% male and $56.5 \%$ female) with an average age of $51.6(\mathrm{SD}=14.1)$. A majority of the respondents were Florida residents (87.0\%). More than half of the sample (56.5\%) were MM qualified physicians in FL, 30.5\% were other physicians or clinicians, $21.7 \%$ were MM patients, $17.4 \%$ were owners/business persons in the marijuana industry, $10.9 \%$ were dispensary staff, $10.9 \%$ were staff in a medical clinic, and some indicated others. Participants were able to choose all options that applied to them (e.g., some of them were dispensary staff as well as MM patients). Com- 
Table 1. Demographic characteristics of study participants $(N=$ 46)

\begin{tabular}{|c|c|c|}
\hline Demographic & $N$ & $\%$ \\
\hline \multicolumn{3}{|l|}{ Gender } \\
\hline Male & 20 & 43.5 \\
\hline Female & 26 & 56.5 \\
\hline Age (mean $\pm \mathrm{SD})$ & $51.6 \pm 14.1$ & \\
\hline \multicolumn{3}{|l|}{ FL resident } \\
\hline Yes & 40 & 87.0 \\
\hline No & 6 & 13.0 \\
\hline \multicolumn{3}{|l|}{ Occupation } \\
\hline Cannabis certified physician in FL & 26 & 56.5 \\
\hline Other physician or clinician & 13 & 30.5 \\
\hline Dispensary staff & 5 & 10.9 \\
\hline Staff in medical clinic & 5 & 10.9 \\
\hline $\begin{array}{l}\text { Owner/businessperson in marijuana } \\
\text { industry }\end{array}$ & 8 & 17.4 \\
\hline Medical marijuana patient & 10 & 21.7 \\
\hline Professor & 1 & 2.2 \\
\hline Did not check any occupation & 1 & 2.2 \\
\hline \multicolumn{3}{|l|}{ Main practice area, if a physician ${ }^{a}$} \\
\hline Family practice & 7 & 24.1 \\
\hline Pain specialist & 5 & 17.2 \\
\hline Emergency medicine & 2 & 6.9 \\
\hline Medical marijuana only & 3 & 10.3 \\
\hline
\end{tabular}

One participant did not report age and 1 physician did not report practice area. Respondents were able to select $>1$ occupation, so values do not total $100 \%$. $^{\text {a }}$ There was 1 provider from each of the following practice areas: Orthopedics, Anesthesiology, Internal medicine, Pediatrics, Functional medicine, RN, OBGYN, Neurosurgery, Integrative/Antiaging medicine, Endocrinology, Addiction, and Pain.

plete demographic information is summarized in Table 1 . The medical specialties of the physicians were diverse, with the most prevalent being family medicine (24.1\%). Those who were MM physicians or dispensary workers $(n=32)$ were asked about the number of years of experience they had interacting with patients who use MM: $28.1 \%$ had $<1$ year of experience, $6.3 \%$ had 1 year, $46.9 \%$ had 2 years of experience, $15.6 \%$ had 3 years, and $3.1 \%$ had 4 years of experience.

\section{Clinical Conditions}

The complete results of priorities for MM research are summarized in Table 2 . The top 9 highly rated conditions where respondents reported a need for more research evidence were chronic pain (3.7 \pm 0.7$)$, cancer $(3.5 \pm 0.8)$, anxiety $(3.4 \pm 0.8)$, posttraumatic stress disorder (PTSD) (3.4 \pm 0.7$)$, Alzheimer's/dementia (3.2 \pm 0.8$)$, depression (3.2 \pm 0.7$)$, epilepsy/seizure disorders $(3.1 \pm 0.8)$, insom- nia (3.1 \pm 0.9$)$, and Parkinson's disease $(3.1 \pm 0.8)$. Conditions like amyotrophic lateral sclerosis $(2.4 \pm 1)$, HIV/ AIDS $(2.5 \pm 1)$, and glaucoma $(2.5 \pm 1)$ received lower ratings.

\section{Safety Issues}

When asked about priorities for research related to safety issues, "dosing and/or medical marijuana product choice" (3.7 \pm 0.5$)$, "complications from smoking or vaping" (3.6 \pm 0.7$)$, and "drug interactions with prescription medications" (3.5 \pm 0.6$)$ received the highest ratings, whereas "cyclic vomiting syndrome" $(2.3 \pm 0.9)$, "potential for addiction (cannabis use disorder)" (2.7 \pm 1.1$)$, and "falls, balance problems" ( $2.8 \pm 0.9)$ were not rated as highly.

\section{Marijuana Types}

Among the priorities for research related to different types of marijuana, the top rated were "different THC/ CBD ratios" $(3.5 \pm 0.7)$, followed by "different modes of consumption" (3.4 \pm 0.7$)$, "different terpenes" (3.4 \pm 0.7$)$, and "marijuana supplied or distributed by Medical Marijuana Treatment Clinics (MMTC) in Florida" (3.3 \pm 0.8$)$. Research on "marijuana supplied by the National Institutes of Health $(\mathrm{NIH})$ " $(2.5 \pm 1.1)$ and "marijuana obtained from illicit (street) sources" (2.5 \pm 1$)$ was not perceived as high priorities for research.

\section{Study Populations}

When asked about research related to types of study populations, research in middle aged/older adults (3.4 \pm $0.6)$, adolescents/young adults $(3.3 \pm 0.8)$, persons in nursing homes $(3.2 \pm 0.7)$, and pregnant women (3.1 \pm 0.8 ) was all perceived to be important topics for research.

\section{Discussion}

This study identifies specific MM research topics that various stakeholders perceived as most important. Respondents indicated that research should be prioritized across a variety of areas. The results are consistent with the findings of the 2017 survey of the California Pharmacy Association [3]; however, this study contains a more detailed list of priorities under 5 different broad categories and lists distinct health conditions rather than using the umbrella term "effect on specific diseases." Thus, findings from this study could provide more specific guidance on the types of MM research that is most needed based on various stakeholders' perspective. 
Table 2. Ratings of the following priorities for research related to different types of medical marijuana, study populations, and strategies to improve health outcomes

\begin{tabular}{|c|c|c|}
\hline & Mean & $\mathrm{SD}$ \\
\hline \multicolumn{3}{|l|}{ Condition } \\
\hline Chronic pain & 3.7 & 0.7 \\
\hline Cancer & 3.5 & 0.8 \\
\hline Anxiety & 3.4 & 0.8 \\
\hline PTSD & 3.4 & 0.7 \\
\hline Alzheimer's/dementia & 3.2 & 0.8 \\
\hline Depression & 3.2 & 0.7 \\
\hline Epilepsy/seizure disorders & 3.1 & 0.8 \\
\hline Insomnia & 3.1 & 0.9 \\
\hline Parkinson's disease & 3.1 & 0.8 \\
\hline Multiple sclerosis & 3 & 0.8 \\
\hline Terminal conditions & 3 & 1 \\
\hline Autism & 2.9 & 0.9 \\
\hline Crohn's disease & 2.8 & 0.8 \\
\hline Nausea/vomiting & 2.6 & 0.9 \\
\hline Glaucoma & 2.5 & 1 \\
\hline HIV/AIDS & 2.5 & 1 \\
\hline Amyotrophic lateral sclerosis & 2.4 & 1 \\
\hline $\begin{array}{l}\text { Other (includes menstrual issues, autoimmune diseases Hashimotos, } \\
\text { diabetes, and rheumatoid arthritis) }\end{array}$ & 3.5 & 0.8 \\
\hline \multicolumn{3}{|l|}{ Priorities for research related to safety issues } \\
\hline Dosing and/or medical marijuana product choice & 3.7 & 0.5 \\
\hline Complications from smoking or vaping marijuana & 3.6 & 0.7 \\
\hline Drug interactions with prescription medications & 3.5 & 0.6 \\
\hline Research on marijuana and driving & 3.1 & 0.9 \\
\hline Simultaneous use with alcohol or other drugs & 3 & 0.9 \\
\hline Schizophrenia and/or psychosis & 3 & 0.9 \\
\hline Falls, balance problems & 2.8 & 0.9 \\
\hline Potential for addiction (cannabis use disorder) & 2.7 & 1.1 \\
\hline Cyclic vomiting syndrome & 2.3 & 0.9 \\
\hline \multicolumn{3}{|l|}{ Priorities for research related to different types of medical marijuana } \\
\hline Different THC/CBD ratios & 3.5 & 0.7 \\
\hline Different modes of consumption (smoking, vaping, and concentrates) & 3.4 & 0.7 \\
\hline Different terpenes & 3.4 & 0.7 \\
\hline Marijuana supplied or distributed by MMTCs ${ }^{\mathrm{b}}$ in Florida & 3.3 & 0.8 \\
\hline Research on CBD alone & 3.1 & 0.8 \\
\hline Marijuana supplied by National Institutes of Health & 2.5 & 1.1 \\
\hline Marijuana obtained from illicit (street) sources & 2.5 & 1 \\
\hline \multicolumn{3}{|l|}{ Priorities for research related to types of study populations } \\
\hline Research in middle aged/older adults & 3.4 & 0.6 \\
\hline Research in adolescents/young adults & 3.3 & 0.8 \\
\hline Research in persons in nursing homes & 3.2 & 0.7 \\
\hline Research in pregnant women & 3.1 & 1 \\
\hline \multicolumn{3}{|l|}{ Priorities for research related to other potential areas for clinical research } \\
\hline Research on the human endocannabinoid system & 3.6 & 0.5 \\
\hline Research to improve clinical training for providers or dispensary workers & 3.4 & 0.7 \\
\hline $\begin{array}{l}\text { Research to improve clinical practice (e.g., medical records, follow-up, } \\
\text { and provider training) }\end{array}$ & 3.3 & 0.8 \\
\hline $\begin{array}{l}\text { Research to obtain "real-time" information from patients daily lives } \\
\text { (e.g., using mobile apps) }\end{array}$ & 3.1 & 0.9 \\
\hline
\end{tabular}

Rating scale: 1 = least important, $2=$ somewhat important, $3=$ important, and $4=$ most important. Participants

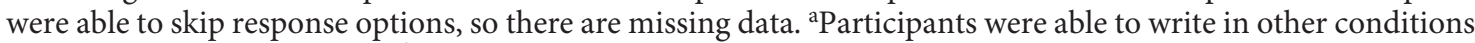
they thought were important. ${ }^{\mathrm{b}}$ MMTC, Medical Marijuana Treatment Center. 


\section{Clinical Conditions}

The top-rated conditions perceived as a priority for research were chronic pain, cancer, anxiety, PTSD, Alzheimer's/dementia, depression, epilepsy/seizure disorders, insomnia, and Parkinson's disease. Interestingly, out of the aforementioned list, 4 of them were symptoms. Chronic pain received the highest rating, which indicates that most respondents need more information on this topic. Chronic pain is the most commonly reported condition for MM use $[10,11]$, and thus it is reasonable that there would be a strong interest in this area. Evidence for dosing and considerations for route of administration is limited [12]. Moreover, there have been conflicting conclusions regarding the use of cannabis for pain. While the National Academies of Sciences 2017 report states that "there is substantial evidence that cannabis is an effective treatment for chronic pain in adults" [13], the International Association for the Study of Pain presidential task force states that they "do not endorse the general use of cannabis and cannabinoids for pain relief due to the lack of high-quality clinical evidence" [14].

\section{Safety Issues}

As more states continue to legalize marijuana for medical purposes, it is important to take into consideration the safety issues surrounding its use. Findings from this study show that respondents perceived research on "dosing and/or medical marijuana product choice," "complications from smoking or vaping," and "drug interactions with prescription medications" as high priorities. The rise in e-cigarette or vaping use-associated lung injury cases in 2019 [15] as wells as smoking and vaping being common modes of administration for marijuana [16] may explain the rating for "complications from smoking or vaping." While producing rapid onset of effects, users also risk exposure to carcinogens and toxic compounds from combustion when smoking marijuana [17]. In contrast, vaping is perceived to be safer than smoking, but further research is needed to evaluate the possible long-term impact of inhalation as a mode of administration. Research on drug-drug interactions is also of importance; 1 study has identified 57 prescription medications that may possibly have interactions with cannabinoids [18].

\section{Marijuana Types}

Research on THC/CBD ratios, modes of consumption, terpenes, and marijuana supplied by MMTCs was perceived as high priorities for research. Current MM products available in state dispensaries have a great diversity in chemical components (THC/CBD ratios and terpenes) and modes of consumption, yet how the variation is associated with health outcomes remains unknown due to limited research. It is notable that research on marijuana from MMTCs was rated as more needed among this sample than research on marijuana products from other sources (i.e., $\mathrm{NIH}$ and illicit sources) when it is possible that individuals may not solely obtain their products from dispensaries, but from other sources as well. An explanation could be that this is due to the sample being derived from a meeting in which there was a high presence of MMTCs.

\section{Population}

All listed populations (i.e., middle aged/older adults, adolescents/young adults, nursing homes, and pregnant women) were perceived to be important areas of need for research. This finding highlights the importance of understanding the impact MM has on health outcomes across different populations. For example, little is known about the effects of MM on older adults. Studies that examine the adverse effects of marijuana have not normally included this population $[19,20]$, though concerns about increased vulnerability to safety issues due to comorbidities, drug-to-drug interactions, and a reduced drug metabolism exist [20]. High-quality research is needed to fill in the gaps for advancing the understanding of how MM impacts health outcomes among various population groups.

\section{Other Areas for Research}

Respondents were asked about the need for research in other areas including the human ECS, research to improve clinical training for providers or dispensary workers, research to improve clinical practice, and research to obtain real-time information from patients daily lives. All were perceived as important areas of need for research, with the ECS receiving the highest rating. The ECS is involved in regulating various processes including sleep, mood, appetite, memory, reproduction, and infertility $[21,22]$. There have been studies that examined the relationship between the ECS and different health conditions such as neurological diseases [23], fibromyalgia [24], and cancer [25] which support the potential of using cannabinoids to manage various maladies. However, more evidence is needed to increase our understanding of the ECS and the different signaling pathways [21].

\section{Limitations}

There are limitations to this study. We used a convenience sample of conference attendees, the sample size was relatively small, and it is unclear if conference attendees are representatives of other MM stakeholders; how- 
ever, attendees were likely highly engaged with the topic. The majority of our respondents were Florida residents; thus, the results may only generalize to stakeholders in that state. Furthermore, there is a possibility that some respondents may have selected "most important" for all research topics; thus, future studies should consider asking participants to select their top 3 choices and rate their importance. Future research with larger and more representative samples is needed to further validate our findings and identify changing research priorities as they emerge.

\section{Conclusion}

This study provided insights into MM research priorities from the perspective of various stakeholders, including physicians, dispensary owners/staff, and patients. Results from our survey highlighted research priorities to bridge knowledge gaps, provide stakeholders with evidence-based guidance on MM use, and inform allocation of research resources by setting prioritized funding and programming agendas.

\section{Acknowledgments}

We would like to thank all the individuals who participated in our survey. We would also like to thank Christine Frank and Katie Butler for providing data entry and support for this project.

\section{Statement of Ethics}

This study (IRB201902533) was reviewed and received exempt approval by the University of Florida Institutional Review Board prior to survey distribution. Written informed consent was not obtained because this was a completely anonymous survey.

\section{Conflict of Interest Statement}

The authors declare no conflicts of interest.

\section{Funding Sources}

The Consortium for Medical Marijuana Clinical Outcomes Research was funded by the State of Florida.

\section{Author Contributions}

J.J. contributed to data collection, analyzed the data, and wrote the manuscript; R.C. designed the study and contributed to data collection and manuscript revision; A.W. designed the study and contributed to manuscript revision; J.B. and A.G. contributed to study design and manuscript revision; S.J. contributed to the data collection and manuscript revision; Y.W. contributed to the study design, data collection, data interpretation, and manuscript preparation.

\section{References}

1 MacIver B. Marijuana legalization World map: Marijuana Business Times; 2017 Jun 29. Available from: https://www.marijuanabusinesstimes.com/article/marijuana-legalization-world-map/.

2 NCSL. State medical marijuana laws. National conference of state legislators; 2020 Nov 10. Available from: https://www.ncsl.org/research/health/state-medical-marijuana-laws. aspx.

3 Szyliowicz D, Hilsenrath P. Medical marijuana knowledge and attitudes: a survey of the california pharmacists association. J Prim Care Community Health. 2019; 10: 2150132719831871.

4 Sideris A, Khan F, Boltunova A, Cuff G, Gharibo C, Doan LV. New York physicians' perspectives and knowledge of the state medical marijuana program. Cannabis Cannabinoid Res. 2018;3(1):74-84.

5 Carlini BH, Garrett SB, Carter GT. Medicinal marijuana: a survey among health care providers in Washington state. Am J Hosp Palliat Care. 2017;34(1):85-91.
6 Philpot LM, Ebbert JO, Hurt RT. A survey of the attitudes, beliefs and knowledge about medical cannabis among primary care providers. BMC Fam Pract. 2019;20(1):17.

7 Ananth P, Ma C, Al-Sayegh H, Kroon L, Klein $\mathrm{V}$, Wharton C, et al. Provider perspectives on use of medical marijuana in children with cancer. Pediatrics. 2018;141(1):e20170559.

8 Zylla D, Steele G, Eklund J, Mettner J, Arneson T. Oncology clinicians and the Minnesota medical marijuana program: a survey on medical marijuana practice patterns, barriers to enrollment, and educational needs. Marijuana Cannabinoid Res. 2018;3(1):195-202.

9 Braun IM, Wright A, Peteet J, Meyer FL, Yuppa DP, Bolcic-Jankovic D, et al. Medical oncologists' beliefs, practices, and knowledge regarding marijuana used therapeutically: a nationally representative survey study. J Clin Oncol. 2018;36(19):1957-62.

10 Boehnke KF, Gangopadhyay S, Clauw DJ, Haffajee RL. Qualifying conditions of medical cannabis license holders in the United States. Health Affairs. 2019;38(2):295-302.
11 Park JY, Wu LT. Prevalence, reasons, perceived effects, and correlates of medical marijuana use: a review. Drug Alcohol Depend. 2017;177:1-13.

12 Jugl S, Okpeku A, Costales B, Morris E, Alipour-Haris G, Hincapie-Castillo J M, et al. A mapping literature review of medical cannabis clinical outcomes and quality of evidence in approved conditions in the USA from 2016 to 2019. Med Cannabis Cannabinoids. 2021.

13 National Academies of Sciences Engineering and Medicine (U.S.). Committee on the health effects of marijuana: an evidence review and research agenda: the health effects of cannabis and cannabinoids: the current state of evidence and recommendations for research. Washington, DC: The National Academies Press; 2017.

14 IASP Presidential Task Force on Cannabis and Cannabinoid Analgesia International Association for the Study of Pain presidential task force on cannabis and cannabinoid analgesia position statement, PAIN: March 16, 2021 - Volume Articles in Press - Issue. 
15 Outbreak of Lung Injury Associated with the Use of E-Cigarette, or Vaping, Products [Internet]. Centers for Disease Control and Prevention;2020 [updated $2020 \mathrm{Feb} 25$; cited 2021 Jun 10]. Available from: Outbreak of Lung Injury Associated with the Use of E-Cigarette, or Vaping, Products [Internet]. Centers for Disease Control and Prevention;2020 [updated $2020 \mathrm{Feb} 25$; cited 2021 Jun 10]. Available from: https://www.cdc.gov/tobacco/basic_information/e-cigarettes/severelung-disease.html.

16 Romero-Sandoval EA, Kolano AL, AlvaradoVázquez PA. Cannabis and cannabinoids for chronic pain. Curr Rheumatol Rep. 2017; 19(11):67.

17 Singh D, Lippmann S. Vaping medical marijuana. Postgrad Med. 2018;130(2):183-5.
18 Kocis P T, Vrana K. Delta-9-tetrahydrocannabinol and cannabidiol drug-drug interactions. Med Cannabis Cannabinoids. 2020;3: 61-73.

19 Briscoe J, Casarett D. Medical marijuana use in older adults. J Am Geriatr Soc. 2018;66(5): 859-63.

20 Mahvan TD, Hilaire ML, Mann A, Brown A, Linn B, Gardner T, et al. Marijuana use in the elderly: implications and considerations. Consult Pharm. 2017;32(6):341-51.

21 Aizpurua-Olaizola O, Elezgarai I, Rico-Barrio I, Zarandona I, Etxebarria N, Usobiaga A. Targeting the endocannabinoid system: future therapeutic strategies. Drug Discov Today. 2017;22(1):105-10.
22 Raypole C. A simple guide to the endocannabinoid system. Healthline; 2019 May 17. Available from: https://www.healthline.com/ health/endocannabinoid-system\#functions.

23 Iannotti FA, Di Marzo V, Petrosino S. Endocannabinoids and endocannabinoid-related mediators: targets, metabolism and role in neurological disorders. Prog Lipid Res. 2016; 62:107-28.

24 Russo EB. Clinical endocannabinoid deficiency reconsidered: current research supports the theory in migraine, fibromyalgia, irritable bowel, and other treatment-resistant syndromes. Cannabis Cannabinoid Res. 2016;1(1):154-65.

25 Laezza C, Pagano C, Navarra G, Pastorino O, Proto MC, Fiore D, et al. The endocannabinoid system: a target for cancer treatment. Int J Mol Sci. 2020;21(3):747. 